J. Lake Sci.(湖泊科学), 2008, 20(3): 389-395

http://www.jlakes.org. E-mail: jlakes@niglas.ac.cn

(C)2008 by Journal of Lake Sciences

\title{
太湖水体散射特性及其空间分异
}

孙德勇, 李云梅, 王 桥, 乐成峰, 黄昌春, 伍 蓝 (南京师范大学教育部虚拟地理环境重点实验室, 南京 210046)

摘 要: 利用 Wetlabs 公司研制的 AC-S 和 BB9 于 2006 年 10 月 24 日至 11 月 2 日对太湖水体的散射系数和后向散射系数进 行了测量, 在此基础上建立了太湖水体散射系数与后向散射系数之间的关系模型. 用 2 种曲线函数模拟, 即在蓝光波段使用 $S$ 形曲线模型, 在绿光和红光波段使用逆函数模型, 各模型的 $M A P E$ 和 $R M S E$ 变化范围分别为 $0.027-0.156 \mathrm{~m}^{-1} 、 0.005-0.050 \mathrm{~m}^{-1}$, 模型整体预测精度都较高. 研究发现后向散射系数与散射系数的空间分异现象明显, 北部梅梁湾、湖心区、西部及西南部水 域散射较强, 而东太湖、胥口湾等东部水域的散射相对较弱.

关键词: 后向散射系数; 散射系数; 空间分异; 太湖

\section{The scattering characteristics of Lake Taihu waters}

SUN Deyong, LI Yunmei, WANG Qiao, LE Chengfeng, HUANG Changchun \& WU Lan

(Key Laboratory of Virtual Geographic Environment, Ministry of Education, Nanjing Normal University, Nanjing 210046, P.R.China)

Abstract: Based on water inherent optical properties using AC-S and BB9, which were developed by WETlabs Inc, the backscattering and scattering coefficients of Lake Taihu waters had been obtained from Oct. 24th to Nov. 2rd, 2006. Based on data analysis, the models between backscattering coefficients and scattering coefficients had been established. Two kinds of curve functions had been used to simulate, i.e. $S$ curve at blue waveband and inverse function at green and red wavebands. And the change ranges of MAPE and RMSE are $0.027-0.156 \mathrm{~m}^{-1}$ and $0.005-0.050 \mathrm{~m}^{-1}$, which indicated higher accuracy. Meanwhile, marked spatial distribution differences of the backscattering and scattering coefficients were found in Lake Taihu. As far as the entire lake was concerned, the scattering and backscattering coefficients in wester lake regions were higher than those in eastern lake regions. Strong scattering and backscattering were found in Meiliang Bay, center region of lake, western and southwestern lake region, while weak values were in East Lake Taihu and Xukou Bay.

Keywords: Backscattering coefficient; scattering coefficient; spatial difference; Lake Taihu

近些年, 湖泊水色遥感发展迅速, 特别是分析模型的研究愈来愈受到人们的关注 ${ }^{[1-3]}$, 它以水体内光 学传输机理为理论基础，基于水体组分浓度与固有光学特性、表观光学特性之间的关系，模拟水中光场 分布, 进而反演水质参数 ${ }^{\left[{ }^{[}\right]}$. 分析模型需要了解水体固有光学特性, 而散射特性是水体固有光学特性的 主要组成部分, 因此, 对水体散射特性的研究是分析模型建立的基础. 水体散射系数是水中颗粒物对人 射到水中的能量在各个方向被散射的整体反映，而后向散射系数则表征了水中颗粒物将能量散射到出水 方向的能力. 关于二者的关系, 国外学者做过一些研究, 认为对大洋一类水体它们是线性关系. Eurico 等 ${ }^{[5]}$ 利用对密西西比河的实测数据分析了 $443 \mathrm{~nm}$ 处的后向散射系数和散射系数的关系, 提出关系式 $b_{\mathrm{b}}(443)=0.00069+0.01799 b_{\mathrm{p}}(443) \quad\left(r^{2}=0.98\right) ;$ Haltrin 等 ${ }^{[6]}$ 认为二者存在较好的二次函数关系; 宋庆君等 ${ }^{[7]}$ 对黄海、东海海区水体的后向散射系数和散射系数进行研究, 认为黄海、东海海区二者更符合乘幂关系, $b_{\mathrm{bp}}(\lambda)=A b_{\mathrm{p}}(\lambda)^{\mathrm{B}}$. 可见, 不同学者对二者关系的研究结果各不相同, 说明不同研究区域的水体具有不同 的光学特性, 其后向散射与总散射的关系存在一定区域特征.

* 国家自然科学基金项目(40571110)资助. 2007-09-29 收稿; 2007-11-07 修改稿. 孙德勇, 男, 1984 年生, 博士研究生; E-mail: sundeyong1984@163.com. 

本研究区选择太湖, 它地处长江三角洲南部, 是我国五大淡水湖之一, 湖泊面积 $2338.1 \mathrm{~km}^{2}$, 湖泊平 均水深 $1.9 \mathrm{~m}$, 最大水深 $2.6 \mathrm{~m}$, 是典型的浅水湖泊 ${ }^{[8]}$. 其中北部湖区的梅梁湾、竺山湾蓝藻水华频发, 为以 浮游植物占主导的藻型湖泊, 而东太湖则是以水生植物为主导的草型湖泊. 由于水体组分的复杂多样及 空间分布的不均衡性，导致其较大跨度的水体散射特性和显著的空间分异. 本研究利用 Wetlabs 公司的 $\mathrm{AC}-\mathrm{S}$ 和 BB9 实测了太湖水体的散射系数和后向散射系数, 在对它们光谱特性进行分析的基础上，提出了 适合太湖水体的后向散射系数与散射系数的关系模型. 此外, 以波长 $532 \mathrm{~nm}$ 为参考, 分析了全湖范围后 向散射系数和散射系数的空间分异特性，以期深人了解太湖水体散射特性的空间变化规律.

\section{1 材料与方法}

\section{1 采样时间与点位}

于 2006 年 10 月 24 日至 11 月 2 日对太湖 64 个样点进行观测, 采取均匀网格布点, 样点分布如图 1. 测 量的参数包括水中颗粒物的后向散射系数和散射系数, 测量深度设置为 $30 、 60 、 90 、 120 \mathrm{~cm}$, 但样点 37 、 $59 、 62 、 63$ 和 64 水深 $1 \mathrm{~m}$ 左右, 所以数据最深处测到 $90 \mathrm{~cm}$. 将所有样点的各深度后向散射系数和散射系 数取平均作为各样点的后向散射系数和散射系数.

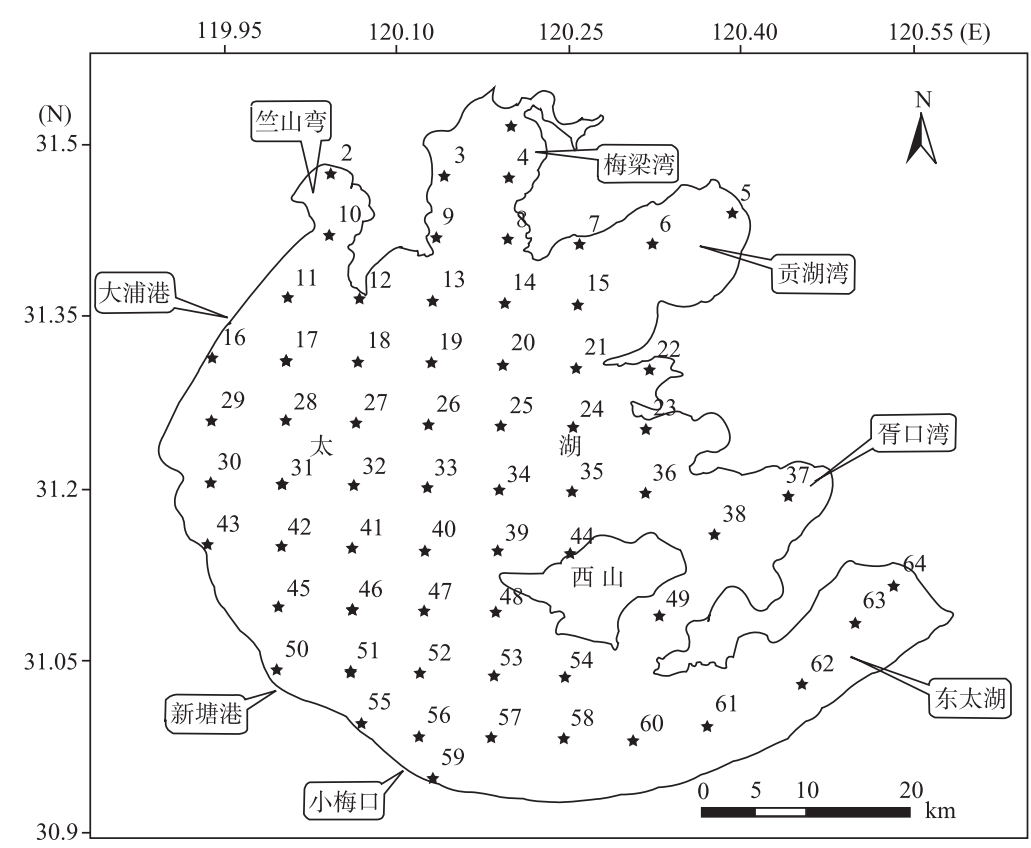

图 1 太湖样点分布

Fig.1 Sampling sites of Lake Taihu

\section{2 散射特性的参数测定}

水中颗粒物散射系数通过 Wetlabs 公司的光谱吸收和衰减仪(AC-S) 获得 ${ }^{[9]}, \mathrm{AC}-\mathrm{S}$ 在可见光波段范围 共有 85 个光谱通道, 光谱分辨率为 $4 \mathrm{~nm}$, 测量精度为 $0.01 \mathrm{~m}^{-1}$, 实验之前, 对仪器进行空气和纯水校准, 校准时每次获得的数值偏差在仪器出厂的要求范围 $\pm 0.005 \mathrm{~m}^{-1}$ 之内. 由 AC-S 直接获得的是水体吸收系数 $a(\lambda)$ 和衰减系数 $c(\lambda)$, 为了得到更为精确的吸收系数数据, 需对吸收系数作温度、盐度和散射纠正 ${ }^{[10]}$ (由于 测量水体是淡水湖泊, 盐度纠正可忽略), 纠正公式如式(1)、(2):

$$
\begin{gathered}
a_{\mathrm{mts}}(\lambda)=a_{\mathrm{m}}(\lambda)-\left[\psi_{\mathrm{t}}\left(t-t_{\mathrm{r}}\right)+\psi_{\mathrm{s}}\left(s-s_{\mathrm{r}}\right)\right] \\
a_{\mathrm{m}}(\lambda)^{*}=a_{\mathrm{rts}}(\lambda)-a_{\mathrm{rts}}\left(\lambda_{\mathrm{ref}}\right)
\end{gathered}
$$


式中, $a_{\mathrm{m}}$ 是测量的吸收系数, 代表了水体总吸收值减去光学纯水的吸收值; $\psi_{\mathrm{t}} 、 \psi_{\mathrm{s}}$ 分别是温度和盐度纠 正系数; $t 、 s$ 分别是野外实测温度和盐度； $t_{\mathrm{r}} 、 s_{\mathrm{r}}$ 分别是纠正的参考温度和盐度； $a_{\mathrm{mts}}$ 是温度和盐度纠正 后吸收系数; $a_{\mathrm{m}}(\lambda)^{*}$ 是纠正后的吸收系数; $\lambda_{\mathrm{ref}}$ 散射纠正的参考波长, 选择 $750 \mathrm{~nm}$. 对衰减系数作同样的 纠正.

经过纠正后的吸收和衰减系数是水体中颗粒物和黄质共同作用的结果, 而黄质对光具有单一的吸收 作用 ${ }^{[16]}$, 所以可以通过衰减系数和吸收系数之差得到水体中颗粒物的散射系数, 如式(3)-(5)所述:

$$
\begin{aligned}
c_{\mathrm{m}}(\lambda)^{*} & =c_{\mathrm{p}}(\lambda)+c_{\mathrm{g}}(\lambda) \\
a_{\mathrm{m}}(\lambda)^{*} & =a_{\mathrm{p}}(\lambda)+a_{\mathrm{g}}(\lambda) \\
b_{\mathrm{p}}(\lambda)^{*} & =c_{\mathrm{m}}(\lambda)+a_{\mathrm{m}}(\lambda)
\end{aligned}
$$

式中, $c_{\mathrm{m}}(\lambda)^{*} 、 a_{\mathrm{m}}(\lambda)^{*}$ 分别是纠正后的衰减和吸收系数; $c_{\mathrm{p}}(\lambda) 、 a_{\mathrm{p}}(\lambda)$ 分别是水中颗粒物的衰减和吸收系数; $c_{\mathrm{g}}(\lambda) 、 a_{\mathrm{g}}(\lambda)$ 分别是黄质的衰减和吸收系数; $b_{\mathrm{p}}(\lambda)$ 是水中颗粒物散射系数.

水体中颗粒物后向散射系数通过 Wetlabs 公司的散射仪(BB9)获得 ${ }^{[11]}$, BB9 共有 9 个光谱通道, 分别 是 400、440、488、510、532、595、660、676 和 $715 \mathrm{~nm}$, 测量精度为 $0.005 \mathrm{~m}^{-1}$. 由于 BB9 使用的是微球 散射体, 由散射引起的衰减部分, 使用 Scale factor(由 Wetlabs 公司提供)纠正成为水体总体散射函数; 接着要对总体散射函数进行吸收纠正, 如式 (6).

$$
\beta(\lambda)^{*}=\beta(\lambda) \exp (0.031 a)
$$

式中, $\beta(\lambda)$ *是吸收纠正后的总体散射函数; $\beta(\lambda)$ 是吸收纠正前的总体散射函数; $a$ 是相应波段的纠正后的 吸收系数 (由 AC-S 获得). 由纠正后得到的总体散射函数, 减掉纯水的体散射函数, 获得颗粒物的体散射 函数 $\beta_{\mathrm{b}}(\lambda)$; 根据公式 $(7)$ 得到颗粒物后向散射系数 $b_{\mathrm{bp}}(\lambda)^{[12]}$.

\section{3 数据处理}

$$
b_{\mathrm{bp}}(\lambda)=2 \pi X \beta_{\mathrm{b}}(\lambda) \quad(X=1.1 \text {, 误差为 } 4 \%)
$$

对于各种参数的分析包括计算最大值、最小值、均值、标准差、线性和非线性拟合、误差分析等利用 SPSS13.0 来完成, 水体散射特性的空间分异等值线图由 ARCGIS9.0 实现. 选择平均相对误差绝对值 $[M A P E$, 公式(8)]和均方根误差 $[R M S E$, 公式(9)]作为模型预测精度的评价标准.

$$
\begin{aligned}
& \text { MAPE }=\frac{1}{n} \sum_{i=1}^{n}\left|\frac{y_{i}-y_{i}^{\prime}}{y_{i}}\right| \\
& \text { RMSE }=\sqrt{\frac{1}{n} \sum_{i=1}^{n}\left(y_{i}-y_{i}^{\prime}\right)^{2}}
\end{aligned}
$$

式中, $n$ 表示样本数量; $y_{i}$ 为样本实测数值; $y_{i}$ 为样本预测数值.

\section{2 结果与分析}

\section{1 后向散射系数与散射系数的光谱特性}

太湖水体后向散射系数光谱随波长的增加大致呈现减小趋势, 且各样点后向散射系数在短波变化明 显, 而在长波却变化微弱(图 2). 表 1 对太湖 64 个样点的后向散射系数作以统计, 各波段的后向散射系数 平均值最大出现在蓝光 $440 \mathrm{~nm}$ 处, 此波段后向散射系数的变化范围为 $0.22-0.54 \mathrm{~m}^{-1}$, 平均值为 $(0.458 \pm 0.065) \mathrm{m}^{-1}$; 随着波长的增加后向散射系数平均值逐渐降低, 在绿光 $532 \mathrm{~nm}$ 处, 后向散射系数的变 化范围为 $0.12-0.25 \mathrm{~m}^{-1}$, 平均值为 $(0.234 \pm 0.008) \mathrm{m}^{-1}$; 到红光 $676 \mathrm{~nm}$ 处, 后向散射系数平均值降低到 $(0.103 \pm 0.001) \mathrm{m}^{-1}$. 选择中心波长 $440 \mathrm{~nm} 、 532 \mathrm{~nm}$ 和 $676 \mathrm{~nm}$ 分别代表蓝、绿和红光波段, 可知蓝光的后向 散射系数是绿光处的 1.96 倍, 绿光的后向散射系数是红光处的 2.27 倍. 此外, 各波段后向散射系数的标准 差从短波到长波依次递减(表 1), 说明各样点后向散射系数从短波到长波逐渐趋于稳定. 相比而言, 散射 系数光谱形态单一, 各样点的散射系数光谱均近似于随波长增大而减小的倾斜直线(图 3), 但各样点散射 系数之间变化较大. 在蓝光 $440 \mathrm{~nm}$ 处, 散射系数的变化范围为 $3.84-53.26 \mathrm{~m}^{-1}$ (平均值 $\left.(26.587 \pm 10.186) \mathrm{m}^{-1}\right)$; 
在绿光 $532 \mathrm{~nm}$ 处, 散射系数的变化范围为 3.32-47.90 $\mathrm{m}^{-1}$ (平均值 $(23.623 \pm 9.142) \mathrm{m}^{-1}$ ); 在红光 $676 \mathrm{~nm}$ 处, 散 射系数的变化范围为 $2.68-40.90 \mathrm{~m}^{-1}$ (平均值 $(19.888 \pm 7.825) \mathrm{m}^{-1}$ ). 由于各湖区水中颗粒物存在着多种主导因 子类型，且悬浮物浓度差异明显，所以造成了太湖水体散射系数显著的相异性 ${ }^{[17]}$.

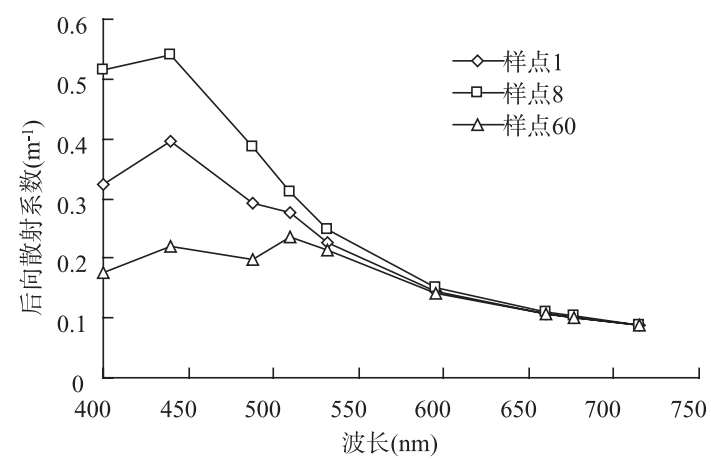

图 2 样点 $1 、 8 、 60$ 的后向散射系数光谱

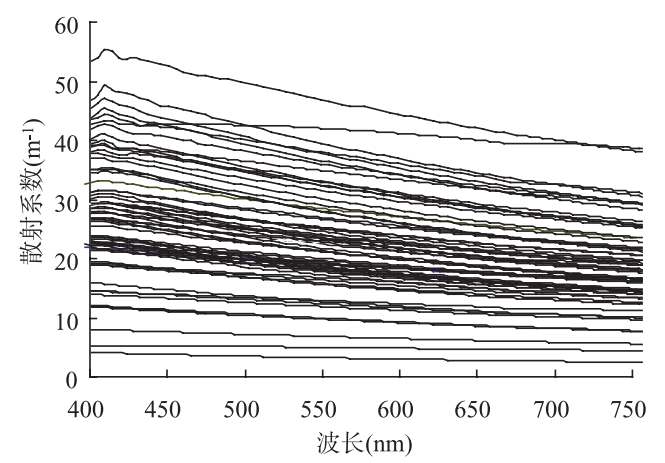

图 3 太湖水体散射系数光谱

Fig.2 Backscattering coefficient spectra at sample 1, 8, 60 Fig.3 Scattering coefficient spectra of Lake Taihu

表 1 各波段后向散射系数的统计分析

Tab.1 Statistical analysis of backscattering coefficients at all wave bands

\begin{tabular}{clllllllll}
\hline \multirow{2}{*}{ 统计量 } & \multicolumn{7}{c}{ 波长 $(\mathrm{nm})$} \\
\cline { 2 - 10 } & 400 & 440 & 488 & 510 & 532 & 595 & 660 & 676 & 715 \\
\hline 最小值 & 0.18 & 0.22 & 0.20 & 0.23 & 0.12 & 0.11 & 0.10 & 0.10 & 0.08 \\
最大值 & 0.51 & 0.54 & 0.39 & 0.31 & 0.25 & 0.15 & 0.11 & 0.11 & 0.09 \\
平均值 & 0.399 & 0.458 & 0.327 & 0.287 & 0.234 & 0.147 & 0.109 & 0.103 & 0.088 \\
标准差 & 0.073 & 0.065 & 0.038 & 0.014 & 0.008 & 0.003 & 0.001 & 0.001 & 0.000 \\
\hline
\end{tabular}

\section{2 后向散射系数与散射系数的关系}

从 64 组实测数据中随机选取 45 组用作二者关系模型的拟合分析, 剩余 19 组用作模型的预测和精 度验证. 选择的拟合模型有一元线性、二次函数、三次函数、S 形曲线、幂函数和逆函数模型, 分别对 9 个波段的后向散射系数和散射系数进行函数拟合, 并通过模型评价指标(选择模型的评价指标有决定系 数 $R^{2}$ 、回归估计的标准误差 $S$ 和 $F$ 显著性检验)对各模型拟和效果进行分析，如表 2. 前人提出的一元线 性、二次函数和幂函数模型对太湖水体的拟和效果不好, 一元线性模型决定系数 $R^{2}$, 从短波到长波呈逐 渐递减趋势, 最大值为 $400 \mathrm{~nm}$ 的 0.755 , 仍比其他模型 $400 \mathrm{~nm}$ 处的 $R^{2}$ 低的很多, 到红光波段 $715 \mathrm{~nm}$ 处已 经减小到 0.143 ; 幂函数模型 $R^{2}$ 较一元线性模型有所提高，大体上从短波到长波呈递减趋势，最大值 $400 \mathrm{~nm}$ 处 0.866 , 最小值 $715 \mathrm{~nm}$ 处 0.486 , 然而模型回归估计的标准误差 $S$ 却较大，特别在蓝光波段，最大 的 $S$ 值达到了 0.119 , 整体考虑幂函数模型也不够理想; 二次函数和三次函数模型的 $R^{2}$ 在蓝光波段较高, 且 $S$ 值也较小，但并不是最佳的; 相比之下, $S$ 形曲线模型在蓝光波段表现最佳，模型的 $R^{2}$ 在 $400 、 440$ 、 488 和 $532 \mathrm{~nm}$ 分别为 $0.933 、 0.947 、 0.951$ 和 0.981 , 对应的 $S$ 值分别为 $0.084 、 0.066 、 0.051$ 和 0.025 , 且 有很大的 $F$ 检验值, 因此对于上述 4 个波段, 太湖水体后向散射系数和散射系数的最佳拟合模型为 $S$ 形 曲线模型. 在绿光和红光波段, 对应 BB9 的后 5 个波段, 即 532、595、660、676 和 715nm, 逆函数模型 的拟合效果要好于 $S$ 形曲线模型, 逆函数模型不但 $R^{2}$ 略高于 $S$ 形曲线模型的, $S$ 值也明显比 $S$ 形曲线模型 的小很多, 同时 $F$ 检验值也较高, 因此, 对于太湖水体在红光波段, 后向散射系数和散射系数的最佳拟合 模型应选择逆函数模型. 值得一提的是, 在 $532 \mathrm{~nm}$ 处逆函数模型和 $S$ 形曲线模型的决定系数和 $F$ 检验值 几乎相同, 但回归估计的标准误差 $S$ 明显小于 $S$ 形曲线模型, $S$ 值分别为 0.004 和 0.025 , 所以选择最佳的 逆函数模型. 由此可知, 太湖水体的后向散射系数和散射系数之间的关系可以用 2 种曲线函数模拟, 即在 
表 2 各波段后向散射系数和散射系数模型拟合结果的评价分析

Tab.2 Evaluation analysis of all models between backscattering and scattering coefficients

\begin{tabular}{|c|c|c|c|c|c|c|c|c|c|}
\hline \multirow{2}{*}{ 模型 } & \multicolumn{9}{|c|}{ 波段(nm) } \\
\hline & 400 & 440 & 488 & 510 & 532 & 595 & 660 & 676 & 715 \\
\hline \multirow[t]{3}{*}{ 一元线性 } & $R^{2}=0.755$ & $R^{2}=0.602$ & $R^{2}=0.687$ & $R^{2}=0.456$ & $R^{2}=0.419$ & $R^{2}=0.330$ & $R^{2}=0.264$ & $R^{2}=0.267$ & $R^{2}=0.143$ \\
\hline & $S=0.040$ & $S=0.049$ & $S=0.028$ & $S=0.024$ & $S=0.017$ & $S=0.009$ & $S=0.005$ & $S=0.003$ & $S=0.001$ \\
\hline & $F=132.197$ & $F=64.934$ & $F=94.282$ & $F=35.982$ & $F=31.010$ & $F=21.165$ & $F=15.451$ & $F=15.633$ & $F=7.150$ \\
\hline \multirow{3}{*}{ 二次函数 } & $R^{2}=0.906$ & $R^{2}=0.871$ & $R^{2}=0.911$ & $R^{2}=0.798$ & $R^{2}=0.749$ & $R^{2}=0.689$ & $R^{2}=0.626$ & $R^{2}=0.604$ & $R^{2}=0.537$ \\
\hline & $S=0.025$ & $S=0.028$ & $S=0.015$ & $S=0.015$ & $S=0.012$ & $S=0.006$ & $S=0.003$ & $S=0.003$ & $S=0.001$ \\
\hline & $F=203.289$ & $F=142.067$ & $F=213.652$ & $F=82.809$ & $F=62.661$ & $F=46.512$ & $\mathrm{~F}=35.194$ & $F=31.989$ & $F=24.373$ \\
\hline \multirow[t]{3}{*}{ 三次函数 } & $R^{2}=0.925$ & $R^{2}=0.934$ & $R^{2}=0.944$ & $R^{2}=0.933$ & $R^{2}=0.893$ & $R^{2}=0.866$ & $R^{2}=0.859$ & $R^{2}=0.851$ & $R^{2}=0.830$ \\
\hline & $S=0.023$ & $S=0.020$ & $S=0.012$ & $S=0.009$ & $S=0.008$ & $S=0.004$ & $S=0.002$ & $S=0.002$ & $S=0.001$ \\
\hline & $F=168.029$ & $F=192.850$ & $F=230.959$ & $F=190.328$ & $F=114.274$ & $F=88.396$ & $F=83.146$ & $F=78.236$ & $F=66.579$ \\
\hline \multirow[t]{3}{*}{$S$ 形曲线 } & $R^{2}=0.933$ & $R^{2}=0.947$ & $R^{2}=0.951$ & $R^{2}=0.981$ & $R^{2}=0.970$ & $R^{2}=0.958$ & $R^{2}=0.948$ & $R^{2}=0.942$ & $R^{2}=0.892$ \\
\hline & $S=0.084$ & $S=0.066$ & $S=0.051$ & $S=0.025$ & $S=0.025$ & $S=0.020$ & $S=0.014$ & $S=0.011$ & $S=0.006$ \\
\hline & $F=599.287$ & $F=763.032$ & $F=835.124$ & $F=2225.520$ & $F=1393.907$ & $F=969.882$ & $F=776.807$ & $F=704.428$ & $F=353.451$ \\
\hline \multirow[t]{3}{*}{ 幂函数 } & $R^{2}=0.866$ & $R^{2}=0.790$ & $R^{2}=0.858$ & $R^{2}=0.711$ & $R^{2}=0.692$ & $R^{2}=0.649$ & $R^{2}=0.609$ & $R^{2}=0.612$ & $R^{2}=0.486$ \\
\hline & $S=0.119$ & $S=0.131$ & $S=0.086$ & $S=0.097$ & $S=0.080$ & $S=0.057$ & $S=0.038$ & $S=0.028$ & $S=0.012$ \\
\hline & $F=277.975$ & $F=162.097$ & $F=260.096$ & $F=105.793$ & $F=96.677$ & $F=79.394$ & $F=66.973$ & $F=7.839$ & $F=40.678$ \\
\hline \multirow[t]{3}{*}{ 逆函数 } & $R^{2}=0.737$ & $R^{2}=0.837$ & $R^{2}=0.818$ & $R^{2}=0.973$ & $R^{2}=0.970$ & $R^{2}=0.965$ & $R^{2}=0.955$ & $R^{2}=0.945$ & $R^{2}=0.891$ \\
\hline & $S=0.041$ & $S=0.031$ & $S=0.022$ & $S=0.005$ & $S=0.004$ & $S=0.002$ & $S=0.001$ & $S=0.001$ & $S=0.0001$ \\
\hline & $F=120.615$ & $F=220.716$ & $F=193.798$ & $F=1561.759$ & $F=1394.815$ & $F=1180.015$ & $F=904.999$ & $F=745.365$ & $F=353.101$ \\
\hline
\end{tabular}

蓝光波段使用 $S$ 形曲线模型, 在绿光和红光波段使用逆函数模型, 具体模型参数见表 3. 模型的 $M A P E$ 变 化范围为 0.027-0.156, RMSE 变化范围为 0.005-0.050, 两误差评价指标的最大值和最小值都分别出现在 $440 \mathrm{~nm}$ 处和 $715 \mathrm{~nm}$ 处. 可见, $715 \mathrm{~nm}$ 处模型预测误差最小, 精度最高, 虽然其他波段处模型预测误差高于 $715 \mathrm{~nm}$ 处, 但各模型的整体预测精度都较高(图 4), 因此, 这些模型对于太湖水体后向散射系数和散射系 数之间关系的模式化有一定的参考价值.

表 3 各波段后向散射系数与散射系数的关系模型及模型预测评价

Tab.3 Models between backscattering and scattering coefficients, and their precisions

\begin{tabular}{llll}
\hline 波段 $(\mathrm{nm})$ & \multicolumn{1}{c}{ 模 型 } & MAPE & RMSE \\
\hline \multirow{3}{*}{ 蓝光 } & $\ln \left(b_{\mathrm{bp}}(400)\right)=-0.552-9.390 / \mathrm{b}_{\mathrm{p}}(400)$ & 0.142 & 0.046 \\
& $\ln \left(b_{\mathrm{bp}}(440)\right)=-0.466-7.725 / b_{\mathrm{p}}(440)$ & 0.156 & 0.050 \\
& $\ln \left(b_{\mathrm{bp}}(488)\right)=-0.869-5.740 / b_{\mathrm{p}}(488)$ & 0.111 & 0.030 \\
& $\ln \left(b_{\mathrm{bp}}(510)\right)=-1.061-4.452 / b_{\mathrm{p}}(510)$ & 0.086 & 0.025 \\
& $b_{\mathrm{bp}}(532)=0.258-0.542 / b_{\mathrm{p}}(532)$ & 0.066 & 0.019 \\
绿光 & $b_{\mathrm{bp}}(595)=0.158-0.230 / b_{\mathrm{p}}(595)$ & 0.041 & 0.010 \\
红光 & $b_{\mathrm{bp}}(660)=0.114-0.106 / b_{\mathrm{p}}(660)$ & 0.038 & 0.006 \\
& $b_{\mathrm{bp}}(676)=0.106-0.075 / b_{\mathrm{p}}(676)$ & 0.034 & 0.006 \\
& $b_{\mathrm{bp}}(715)=0.089-0.025 / b_{\mathrm{p}}(715)$ & 0.027 & 0.005 \\
\hline
\end{tabular}



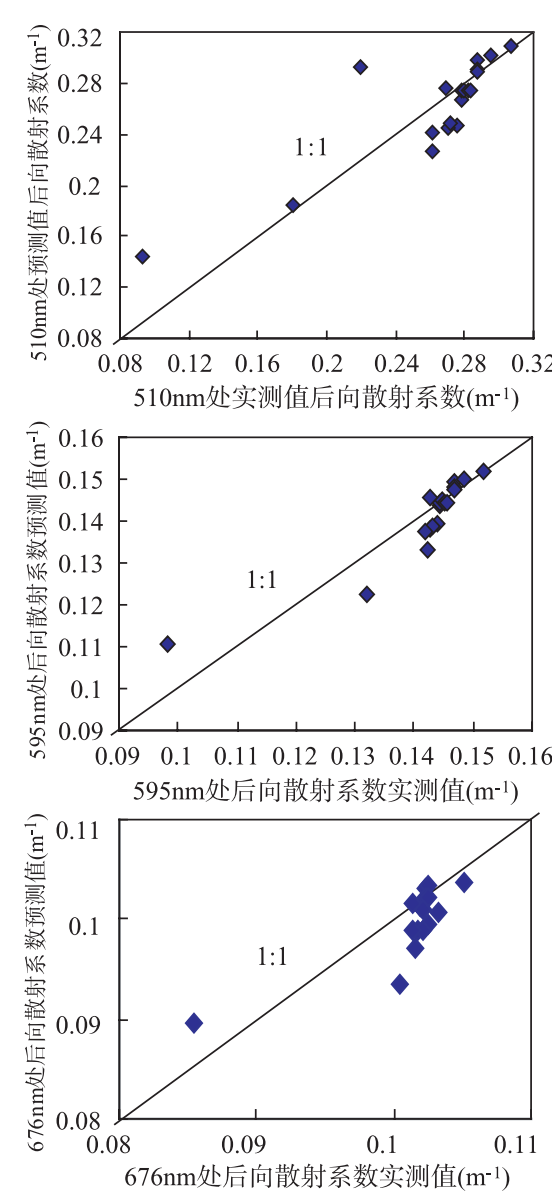

图 4 510、595 和 $676 \mathrm{~nm}$ 处模型预测 值和实测值散点图

Fig.4 Predicted and measured values at $510 \mathrm{~nm}, 595 \mathrm{~nm}, 676 \mathrm{~nm}$

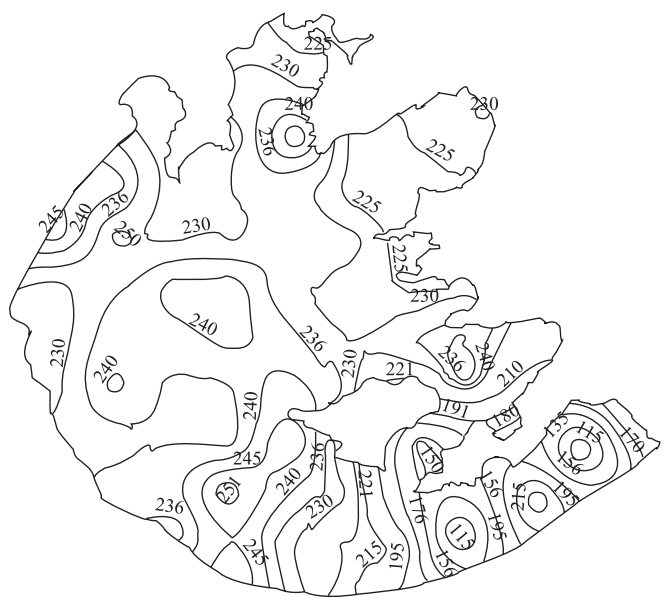

图 5 太湖水体后向散射系数的空间分异

Fig. 5 Spatial differences of backscattering coefficients in Lake Taihu

\section{3 后向散射系数与散射系数的空间分异}

在梅梁湾湖区, 后向散射系数 (以 $532 \mathrm{~nm}$ 为参考)总体趋势呈 现从湾口向湾内递减，湾北部水域的后向散射系数最小，在 $0.225 \mathrm{~m}^{-1}$ 附近变化, 而湾口则达到了 $0.240 \mathrm{~m}^{-1}$ 以上; 贡湖湾后向 散射系数空间分异特征不明显, 多数水域后向散射系数为 $0.225 \mathrm{~m}^{-1}$; 相比之下，大浦港水域后向散射系数存在明显的空间 分异, 从港口向湖心方向后向散射系数从 $0.245 \mathrm{~m}^{-1}$ 依次递减到 $0.230 \mathrm{~m}^{-1}$; 湖心区虽然存在较强的后向散射, 但无明显的空间变 化, 多数水域后向散射系数集中在 $0.240 \mathrm{~m}^{-1}$ 左右; 在整个太湖范 围, 最大的后向散射出现在南部水体, 介于新塘港和小梅口之间, 后向散射系数为 $0.250 \mathrm{~m}^{-1}$, 并且南部水体后向散射系数的空间变 化特征表现为从西向东逐渐递减, 其递减变化范围为 $0.250-0.175 \mathrm{~m}^{-1}$; 全湖最小的后向散射出现在东太湖，后向散射 系数为 $0.115 \mathrm{~m}^{-1}$, 但此湖区后向散射空间分异复杂，没有明显的 变化规律(图 5). 散射系数的空间分异与后向散射系数的存在相 似之处, 同时也表现出一定的差异. 梅梁湾存在较强的水体散射, 散射系数在 $25 \mathrm{~m}^{-1}$ 附近变化, 且也表现出从湾口向湾内逐渐递减 的趋势; 贡湖湾水体散射弱于梅梁湾, 但其变化规律与之类似, 散射系数从湾内向湾口递增; 同时竺山湾也表现相似的变化规 律, 散射系数从湾北的 $19 \mathrm{~m}^{-1}$ 增加到湾口的 $23 \mathrm{~m}^{-1}$; 湖心区一直维 持较高的散射, 散射系数在 $25 \mathrm{~m}^{-1}$ 左右变化, 呈现由西南向东北 衰减; 大浦港水域散射系数达到了 $29 \mathrm{~m}^{-1}$, 处于较高的散射水平, 但其空间分异没有后向散射系数明显; 与后向散射系数相似, 散 射系数最大的区域也出现在太湖南部的新塘港和小梅口附近, 并表现从西向东递减的趋势; 东太湖是全湖散射系数最小的区 域, 其空间分异显著, 从西向东依次递增(图 6). 由此可见, 无论 后向散射系数还是散射系数都存在较为明显的空间分异特性, 即太湖不同湖区的水体散射特性差异较大, 这是太湖水体光学 特性之一, 同时也反映出各湖区水中悬浮颗粒的分布差异.

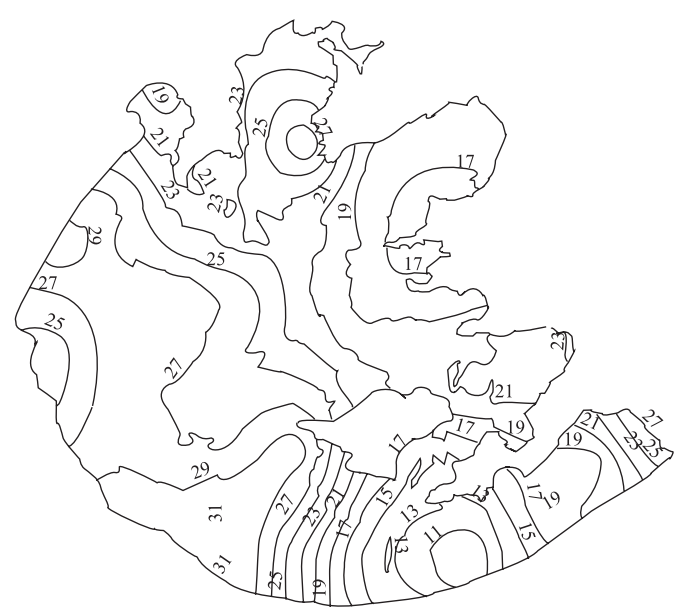

图 6 太湖水体散射系数的空间分异

Fig.6 Spatial differences of scattering coefficients in Lake Taihu 
就全湖范围来说，水体散射呈较为明显的东西差异性，北部梅梁湾、湖心区、西部及西南部水域都 表现较强的散射，而东太湖、胥口湾等东部水域的散射弱于西部. 湖心区由于湖面开阔，底泥受风浪摚动 的影响较大, 其再悬浮增加了水体中悬浮物浓度, 增强了水下光的衰减 ${ }^{[13-15]}$, 这是导致湖心区强水体散射 的主要原因; 西南湖区一方面由于人湖径流携带了较多的悬浮颗粒物, 另一方面是因为此水域开阔, 受 风浪的影响比较大, 表现较强的水体散射; 而东太湖主要是由于其处于一狭长的湾, 风浪比较小, 加之 沉水植物对沉积物再悬浮的抑制作用造成颗粒物浓度小, 散射和后向散射系数比较小.

\section{3 结论}

(1) 后向散射系数从蓝光到绿光再到红光波段呈现约半数递减的规律, 且各波段后向散射系数的标 准差从短波到长波依次递减, 说明各样点后向散射系数从短波到长波逐渐趋于稳定. 散射系数光谱形态 单一, 各样点的散射系数光谱均近似于随波长增大而减小的倾斜直线, 但各样点散射系数之间变化较大.

(2) 太湖水体的后向散射系数和散射系数之间的关系可以用 2 种曲线函数模拟，即在蓝光波段使用 $S$ 形曲线模型, 在绿光和红光波段使用逆函数模型. 各模型的 $M A P E$ 变化范围为 $0.027-0.156, R M S E$ 变化范 围为 $0.005-0.050$, 可见各模型的整体预测精度都较高, 所以这些模型对参数化后向散射系数和散射系数 之间的关系有一定的参考价值.

(3) 后向散射系数与散射系数的空间分异现象明显, 部分水域散射特性变化规律有序; 而就全湖范 围来说, 水体散射呈较为明显的东西差异性, 北部梅梁湾、湖心区、西部及西南部水域散射较强, 而东太 湖、胥口湾等东部水域的散射相对较弱.

致谢: 感谢参加太湖实验的所有人员的辛勤工作, 感谢王海君、王利珍、杨大伟、王搻和陆皖宁在数据 处理和分析中提供的帮助.

\section{4 参考文献}

[1] 李云梅, 黄家柱, 韦玉春等. 用分析模型方法反演水体叶绿素的浓度. 遥感学报, 2006, 10(2): 169-175.

[2] 马荣华, 唐军武. 湖泊水色遥感参数获取与算法分析. 水科学进展, 2006, 17(5): 720-726.

[3] 李云梅, 黄家柱, 陆皖宁等. 基于分析模型的太湖悬浮物浓度遥感监测. 海洋与湖沼, 2006, 37(2): 171-177.

[4] Forget P, Broche P, Naudin JJ. Reflectance sensitivity to solid suspended sediment stratification in castal water and inversion: a case study. Remote sensing of environment, 2001, 77: 92-103.

[5] Eurico JD, Sa RL Miller. Bio-optical properties in waters influenced by the Mississippi River during low flow conditions. Remote Sensing of Environment, 2003, 84: 538-549.

[6] Haltrin Vladimir I, Lee Michael E, Shybanov Eugeny B et al. Relationship between backscattering and beam scattering coefficients derived from new measurements of light scattering phase functions. Spie Ocean Optics XVI. Society of Photo-Optical Instrumentation Engineers.Santa Fe: 2002.

[7] 宋庆君, 唐军武. 黄海、东海海区水体散射特性研究. 海洋学报, 2006, 28(4): 56-63.

[8] 秦伯强, 胡维平, 陈伟民编著. 太湖水环境演化过程与机理. 北京: 科学出版社, 2004: 1-2.

[9] Moore C, Barnard A, Hankins D et al. Spectral Absorption and Attenuation Meter (ac-s) User's Guide, Revision A. America: WET Labs Inc, 2004: 5-20.

[10] Zaneveld JRV, Kitchen JC, Moore CC et al. Scattering error correction of reflecting-tube absorption meters. Proceedings of SPIE, 1994, 2258: 44-55.

[11] Moore C, Barnard A, Hankins D et al. Scattering Meter (BB9) User's Guide, Revision A. America: WET Labs Inc, $2005:$ 2-13.

[12] Boss E, Pegau S. The relationship of light scattering at an angle in the backward direction to the backscattering coefficient. Applied Optics, 2001, 40(30): 5503-5507.

[13] Hellestr o m T. The effect of suspension on algal production in shallow lake. Hydrobiologia, 1991, 213: 183-190.

[14] 张运林, 秦伯强, 陈伟民等. 悬浮物浓度对水下光照和初级生产力的影响. 水科学进展, 2004, 15(5): 615-620.

[15] 杨顶田, 陈伟民, 张运林等. 太湖梅梁湾水体中悬浮质及光谱的分布特征. 生态科学, 2002, 21(4): 289-293.

[16] 俞 宏, 蔡启铭, 吴敬禄. 太湖水体吸收系数与散射系数的特征研究. 水科学进展, 2003, 14(1): 46-49.

[17] 孙德勇, 李云梅, 乐成峰等. 太湖水体散射特性及其与悬浮物浓度关系模型. 环境科学, 2007, 28(12): 24-3 0. 


\section{“地理环境变化研究”学术研讨 一一暨施雅风院士九十华诞座谈会在南京举行}

3月21日是我国著名的自然地理学家施雅风院士九十华诞. 3 月 20 日, “地理环境变化研究”学术研讨 暨施雅风院士九十华诞座谈会在中国科学院南京地理与湖泊研究所隆重举行. 应邀出席座谈会的为在宁 部分与施老有长期科研合作关系的著名学者, 包括赵其国院士、王颖院士、朱大奎教授、王富荣教授、 朱诚教授、徐琪研究员、唐领余研究员、王建教授、张忍顺教授、李世杰研究员、屠清䒨研究员、余之 祥研究员、沈道齐研究员、王苏民研究员、朱季文研究员、季子修研究员、陈家其研究员等老同志, 以 及施老在南京培养的部分学生等 30 多人。中共中央政治局委员、书记处书记、中央组织部部长李源潮同 志专程发来亲笔书写的生日贺卡; 中国科学院地学部办公室专门打来电话祝贺.

座谈会由中国科学院南京地理与湖泊研究所杨桂山所长主持, 他首先对各位学者应邀参加座谈会表 示热烈欢迎，并简要介绍施老工作经历和成就，代表研究所全体职工向施老 90 华诞表示最衰心的祝贺， 并祝愿他老人家健康长寿、吉祥如意!

施雅风院士结合科研和人才培养工作回忆了他在浙江大学史地系学习和参加工作 60 余年来的诸多 往事, 对曾经给予自己帮助的各位同事表示深深的感谢. 随后大家踊跃争相发言, 畅谈了与施老工作、 学习和接触的点点滴滴和难忘的场景, 座谈会自始至终洋溢着喜庆和热烈的气氛. 大家对施老又红又 专、爱国爱党的崇高境界, 为人正派、淡泊名利的高尚品德, 尊老携幼、乐于助人的无私精神以及敏锐 的学术洞察力、学术研究勇于开拓创新、重视野外实践、严谨治学和对科学毕生追求等方面给予了极高 的评价.

施雅风院士 1944 年浙江大学研究生毕业后, 即进入中国地理研究所工作. 1949 年后, 历任中国科学 院地理研究所助理研究员、副研究员. 1958 年以后组织祁连山等西北冰川考察, 发起冻土与泥石流研究, 创建中国科学院兰州冰川冻土研究所, 任研究员、所长与名誉所长. 1980 年当选为中国科学院学部委员、 地学部副主任. 曾兼任中国地理学会理事长. 主编专著 16 部, 发表论文 200 多篇, 成果分别获得国家自 然科学三等奖与一等奖, 冰川编目获国家科技进步二等奖. 2006 年获得甘肃省科技功臣称号.

1985 年施雅风院士兼任中国科学院南京地理与湖泊研究所研究员, 他洞察到湖泊研究在全球变化研 究中的重要性, 以他高超的组织能力和学术影响, 积极组织队伍先后在新疆、青藏高原开展湖泊水资源、 湖泊沉积深钻研究; 同时在东部他亲自挂帅开展海平面变化对水资源、港口工程等的影响的研究, 做出 了有国际影响的成果, 积极推动了中国科学院南京地理与湖泊研究所科研工作走向学术前缘.

1991 年《湖泊科学》创刊后, 施老出任第 1、2、3 届编辑委员会主任, 为《湖泊科学》的发展作出 了极大贡献。他高瞻远瞩, 引导《湖泊科学》关注譬如全球变化的湖泊响应、湖泊富营养化发生机制等 若干热点领域. 在办刊理念方面, 要求解放思想, 进一步拓宽思路, 积极探索, 加强对湖泊环境、生态系 统退化诸多问题发生过程与机制, 以及生态学和地理学等基础理论领域的报道力度, 贯彻以报道基础和 应用基础研究成果为主, 同时及时反映湖泊治理和环境保护等管理、实践领域的需求和实证研究成果. 《湖泊科学》目前已经成长为国内湖泊科学领域最权威的学术期刊, 其学术影响力不断扩大, 根据中国 科学引文数据库的统计, 2000 年至今《湖泊科学》的影响因子一直位居全国前 100 名, 这是与施老多年 的努力和引导分不开的.

施老不仅是一位充满激情和奉献精神的老革命工作者, 也是一位不断创新的科学领导者, 同时是一 位长期奋斗在科研一线的科学工作者, 是中国知识分子一个时代的杰出代表. 他所体现出的无私奉献、 不断创新、勤恳工作的精神, 他对学科发展和科研工作的高瞻远瞩、严谨的治学态度、对人才培养和科 研团队建设的远见卓识, 都是我们学习的榜样和楷模. 